\title{
Estimating the cost-effectiveness of the Sodium Reduction in Communities Program
}

\author{
Benjamin Yarnoff 1 ,* $\odot$, Emily Teachout ${ }^{2,3} \odot$, Kara MacLeod ${ }^{2,4}$, John Whitehill2, \\ Julia Jordan ${ }^{2}$, Zohra Tayebali ${ }^{1}$ and Laurel Bates ${ }^{1}$ \\ ${ }^{1}$ RTI International, Research Triangle Park, NC 27709, USA: ${ }^{2}$ Centers for Disease Control and Prevention, Atlanta, \\ GA, USA: ${ }^{3}$ Deloitte Consulting, LLP, London, UK: ${ }^{4}$ HHRC, Inc., Atlanta, GA, USA
}

Submitted 23 March 2021: Final revision received 12 August 2021: Accepted 27 September 2021: First published online 25 0ctober 2021

\begin{abstract}
Objective: This study assessed the cost-effectiveness of the Centers for Disease Control and Prevention's (CDC's) Sodium Reduction in Communities Program (SRCP).

Design: We collected implementation costs and performance measure indicators from SRCP recipients and their partner food service organisations. We estimated the cost per person and per food service organisation reached and the cost per menu item impacted. We estimated the short-term effectiveness of SRCP in reducing sodium consumption and used it as an input in the Prevention Impact Simulation Model to project the long-term impact on medical cost savings and quality-adjusted life-years gained due to a reduction in CVD and estimate the cost-effectiveness of SRCP if sustained through 2025 and 2040.

Setting: CDC funded eight recipients as part of the 2016-2021 round of the SRCP to work with food service organisations in eight settings to increase the availability and purchase of lower-sodium food options.

Participants: Eight SRCP recipients and twenty of their partners.

Results: At the recipient level, average cost per person reached was $\$ 10$, and average cost per food service organisation reached was $\$ 42917$. At the food service organisation level, median monthly cost per food item impacted by recipe modification or product substitution was $\$ 684$. Cost-effectiveness analyses showed that, if sustained, the programme is cost saving (i.e. the reduction in medical costs is greater than the implementation costs) in the target population by $\$ 1.82$ through 2025 and $\$ 2.09$ through 2040 .

Conclusions: By providing evidence of the cost-effectiveness of a real-world sodium reduction initiative, this study can help inform decisions by public health organisations about related CVD prevention interventions.
\end{abstract}

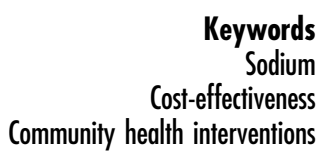

eywords

Community health interventions
High sodium intake can lead to hypertension and increase the risk for heart disease and stroke ${ }^{(1,2)}$. In 2014, US adults between the ages of 20 and 69 consumed sodium at an average of $3608 \mathrm{mg} / \mathrm{d}^{(3)}$. The 2020-2025 Dietary Guidelines for Americans ${ }^{(4)}$ and the Dietary Reference Intakes for Sodium and Potassium ${ }^{(5)}$ recommend adults consume no more than $2300 \mathrm{mg} / \mathrm{d}$ of sodium each day. It has been estimated that every $1000 \mathrm{mg} / \mathrm{d}$ increase from this recommendation increases the risk of CVD events by $17 \%{ }^{(2)}$. A large proportion of the sodium consumed in the USA comes from processed foods and foods prepared in restaurants and cafeteria settings - sources over which consumers have little control ${ }^{(6)}$. Accordingly, this gap between recommended intake and actual intake among US adults requires a public health approach that expands beyond a focus on individual behaviour change. Public health approaches to sodium reduction should include strategies that focus on reducing the sodium content in prepackaged and pre-prepared foods ${ }^{(7,8)}$.

The Sodium Reduction in Communities Program (SRCP) began as a demonstration project in the USA in 2010 to address this growing public health concern. As part of the 2016-2021 round of SRCP, the Centers for Disease Control and Prevention funded eight recipients, including local and state health departments and a research university, to work with food service organisations in eight 
settings to increase the availability and purchase of lowersodium food options, with the goal of reducing sodium intake to within the recommendation of the 2015-2020 Dietary Guidelines for Americans. The programme focuses on four distinct sodium strategies: (1) implementation of food service guidelines and nutritional standards that include sodium; (2) introduction of meal and menu item modifications; (3) integration of lower-sodium food procurement practices and (4) implementation of behavioural economic strategies to promote lower-sodium items (e.g. placement interventions).

Early outcome data suggest that partnering with local food service organisations to provide consumers with lower-sodium options is an effective strategy to lower population-level sodium consumption ${ }^{(9)}$. However, little is known about the cost-effectiveness of strategies implemented in SRCP, which is important for public health policy and planning decisions. In this study, we aimed to provide this information by estimating the cost of achieving implementation outcomes and the cost-effectiveness of strategies implemented in SRCP. First, we estimated the cost per unit of improvement in implementation outcomes, such as persons reached, and food items affected by sodium reduction efforts. This approach provides evidence of the cost of achieving implementation objectives. Second, we estimated the long-term cost-effectiveness of SRCP by integrating the estimates of short-term implementation outcomes and costs with a simulation model, the Prevention Intervention Simulation Model (PRISM) ${ }^{(10-12)}$. These estimates of cost-effectiveness can be used to support decision-making about future sodium reduction efforts.

\section{Methods}

\section{Programme description}

Eight recipients were funded as part of the 2016-2021 round of SRCP. Funded recipients include state (New York and Oregon) and local (Los Angeles County, Marion County-Indiana, New York City, Seattle and King County, and Philadelphia) public health departments and a research university (University of Arkansas for Medical Sciences). The recipients partnered with food service organisations to implement sodium reduction strategies in $\geq 1$ of eight settings: worksites, hospitals, schools, early childhood education centres, higher-learning institutions, restaurants, emergency food services and distributive or congregate meal sites. Recipients identified and recruited food service organisation partners based on their target populations and partner openness to implementing sodium reduction strategies.

Recipients and their partner food service organisations worked to implement the four strategies of SRCP. Table 1 shows examples of implementation activities for each sodium reduction strategy. Table 2 summarises implementation in each of the eight settings including the number of recipients working in each setting, the number of food service organisations reached in each setting and the number of people reached in each setting. The populations reached in each setting differ most notably in the frequency with which they are reached. For example, schools, early childhood education centres and distributive/congregate meal programmes reach their populations regularly (e.g. schools provide lunch to students every day). Conversely, restaurants may reach different people each day.

\section{Data collection}

\section{Cost data}

We used two different data collection tools to collect data on SRCP implementation costs. The first collected implementation costs from recipients and the second from partner food service organisations. We collected data on implementation costs from recipients using an Excel-based cost-collection instrument. The instrument used an activitybased costing approach ${ }^{(13)}$. Respondents were asked to report all resources (labour and non-labour) used to implement SRCP for six categories: (1) labour; (2) materials, travel and equipment; (3) contracted services; (4) indirect and overhead costs; (5) in-kind labour and (6) in-kind nonlabour. In-kind costs included costs incurred to support programme implementation but not paid for using funds from the cooperative agreement such as staff time paid for by the health department and resources donated by the health department. Within each resource category, respondents were asked to allocate each line item across five main programme activities: (1) building and maintaining partnerships, (2) designing sodium reduction interventions, (3) implementing sodium reduction interventions, (4) performing administrative activities and (5) conducting evaluations. We collected data from the recipients in February 2018 to report all costs incurred to implement the programme from 30 September 2016 through 31 December 2017 (15 months); in February 2019 to report all costs incurred from 1 January 2018 through 31 December 2018 (12 months); and in December 2019 to report all costs incurred from 1 January 2019 through 29 September 2019 (9 months). The funded costs and in-kind costs were similar for the first two reporting periods and lower for the third. Combined, these costs represent implementation costs for the first 36 months of the programme. Data were reported by SRCP programme managers with input from other programme staff for all eight recipients. We provided technical assistance for data collection by answering respondents' questions via email and phone over the data collection period and conducted a data quality review upon submission.

During May-June 2019, we collected data on the in-kind contributions of partner food service organisations to SRCP implementation over the period 30 September 2016 through 30 April 30 2019, using a cost survey. All partner costs were considered in-kind because they were paid 
Table 1 Example implementation activities for each sodium reduction strategy

\begin{tabular}{|c|c|}
\hline Sodium reduction strategy & Example activities \\
\hline $\begin{array}{l}\text { Implementation of food service guidelines and nutri- } \\
\text { tional standards that include sodium }\end{array}$ & $\begin{array}{l}\text { - Using environmental scans to inform recommendations for sodium reduction } \\
\text { improvements in the food service organisations } \\
\text { - Convening meetings with key partners like registered dietitians and food service } \\
\text { personnel to provide unified guidance for nutrition guidelines and other sodium } \\
\text { reduction strategies } \\
\text { - Setting feasible sodium reduction goals by targeting the food categories that offer } \\
\text { the greatest opportunity for reducing sodium (e.g. high sodium ingredients that } \\
\text { affect many menu items) }\end{array}$ \\
\hline Introduction of meal and menu item modifications & $\begin{array}{l}\text { - Developing a culinary food preparation programme where an external chef } \\
\text { educated food service staff on culinary techniques and food preparation practices } \\
\text { to reduce sodium in meals } \\
\text { - Distributing lower-sodium cooking materials including recipes, tool kits and meas- } \\
\text { uring spoons to enable chefs to make lower-sodium meals from scratch } \\
\text { - Conducting skills-based training to enable food service staff to feel more confi- } \\
\text { dent using lower-sodium and healthier alternatives while cooking }\end{array}$ \\
\hline $\begin{array}{l}\text { Integration of lower-sodium food procurement practi- } \\
\text { ces }\end{array}$ & $\begin{array}{l}\text { - Embedding sodium standards within existing and new food services contracts for } \\
\text { cafeterias } \\
\text { - Reviewing product lists and provided food service organisations with a list of } \\
\text { similar products with lower-sodium content } \\
\text { - Developing new procurement relationships with vendors and manufacturers who } \\
\text { carry lower-sodium food items }\end{array}$ \\
\hline $\begin{array}{l}\text { Implementation of behavioural economic strategies } \\
\text { to promote lower-sodium items }\end{array}$ & $\begin{array}{l}\text { - Redesigning spaces by repainting and hanging photos of healthy foods } \\
\text { - Discounting purchases that are part of healthy foods programme } \\
\text { - Removing salt packets from trays and salt shakers from tables so that patrons } \\
\text { must request them }\end{array}$ \\
\hline
\end{tabular}

Table 2 Summary of implementation in each setting, 1 September 2016-31 December 2018

\begin{tabular}{lccr}
\hline Settings & $\begin{array}{c}\text { Number of recipients working in the } \\
\text { setting }\end{array}$ & $\begin{array}{c}\text { Number of food service organisations } \\
\text { reached }\end{array}$ & $\begin{array}{c}\text { Number of people } \\
\text { reached }\end{array}$ \\
\hline Worksites & 1 & 5 & 16000 \\
Hospitals & 2 & 19 & 2246000 \\
Schools & 3 & 218 & 626000 \\
Early childhood education & 1 & 57 & 5000 \\
$\quad$ centres & 3 & 22 & 373000 \\
Higher-learning institutions & 1 & 15 & 5000 \\
Restaurants & 1 & 5 & 228000 \\
Emergency food services & 5 & 188 & 403000 \\
Distributive/congregate meals & 17 & 529 & 3902000 \\
Total & & 5 & 000 \\
\hline
\end{tabular}

*Estimated based on the average number of people served each day in participating food service organisations. Rounded to the nearest thousand.

for by the partner organisations themselves. In the partner food service organisation cost survey, respondents were asked about a set of key sodium reduction activities including implementation of nutrition guidelines, recipe development and modification, changing food procurement practices, modification to food preparation practices, healthy food promotion, meetings and other activities. For each activity, respondents were asked the number and types of staff who worked on the activity, the average monthly number of hours each staff member worked on that activity and the number of months worked by each staff member. Respondents reported the monthly average across the reporting period. Additionally, for each activity, respondents were asked to report any non-labour expenditures like materials and supplies. Participation was voluntary. Recipients provided contact information for forty-five of eighty-eight key partner food service organisations. We sent invitations to those forty-five food service organisations and received completed surveys from twenty ( $44 \%$ ). The only information we had about partner characteristics was the venue in which they worked. We examined the completion rate for each venue to assess potential response bias: six out of eight congregate meal partners, one out of one early childhood education centres, zero out of three emergency food services, three out of ten higher learning institutions, two out of eight hospitals, two out of two restaurants, four out of ten schools and one out of three worksites.

\section{Programme implementation and effectiveness data}

As part of SRCP, recipients conduct programme evaluations including the collection and reporting implementation and short-term effectiveness performance measures at baseline (2015-2016) and each programme year thereafter 
(2016-2017, 2017-2018 and 2018-2019). Centers for Disease Control and Prevention offered a list of implementation and effectiveness outcomes that the programme, as a whole, aims to achieve and ways to measure the performance towards those outcomes. Centers for Disease Control and Prevention provided guidance on data sources and method for computing each performance measure and recipients followed these approaches. Recipients selected target performance measures that fit their needs and capacity levels. Because all recipients did not select the same performance measures to report, data are not available on all measures for all venues. Recipients were encouraged to collect and report performance measure data for all venues in which they worked but some did not collect all measures in all venues. Therefore, performance measures are not representative of all recipient activities. Some recipients reported performance measures even more finely, down to the specific partner food service organisation. For recipient-level analysis, we aggregated partner-level data for each recipient to create a recipient average. For partnerlevel analysis, we utilised these finer data to link partner performance measure data with partner cost data ( $n$ 13).

We used four measures of programme implementation for the analysis of the cost of achieving implementation outcomes in the present study: (1) number of food service organisations reached, defined as the number of food service organisations that partnered with the recipient to implement sodium reduction strategies (reported by recipients for seventeen out of the seventeen venues); (2) number of people reached per day, defined as the average number of people served by partner food service organisations each day computed from sales data provided by food service organizations (reported by recipients for seventeen out of the seventeen venues); (3) number of menu items affected by recipe modification, defined as the number of menu items served by partner food service organisations for which the recipe was modified to reduce sodium computed from recipe data provided by food service organisations (reported by recipients for twelve out of the seventeen venues) and (4) number of menu items affected by procurement changes to substitute ingredients or entire items, defined as the number of menu items served by partner food service organisations that were replaced with a lower-sodium alternative entirely or in part (i.e. one ingredient) through changes in procurement computed from procurement records and menus provided by food service organisations (reported by recipients for fourteen out of the seventeen venues). We also used two short-term programme effectiveness measures as inputs in the analysis of long-term cost-effectiveness in the present study: (1) change in average daily sodium intake as measured by the average sodium content of purchased food, computed from a combination of sales data and menu nutrition data provided by food service organisations (reported by recipients for six out of the seventeen venues); and (2) percentage of people in the targeted food service organisation who purchased lower-sodium items computed from sales data provided by food service organisations (assumed to be the percentage of people reducing sodium consumption) (reported by recipients for fourteen out of the seventeen venues).

\section{Data analysis}

We assessed (1) the cost of achieving implementation outcomes and (2) the potential long-term cost-effectiveness of sodium reduction strategies.

\section{Analysis of the cost of achieving implementation outcomes}

We assessed the costs of a one-unit increase in implementation outcome measures (e.g. person reached) by mapping expenditures reported in the cost study with implementation outcome measures reported by recipients in their performance reporting. We conducted implementation outcome analyses separately for recipients and partner food service organisations that participated in the cost study.

We computed the total cost of all activities and average cost of each activity across recipients. We aggregated total costs across recipients to compute total programme costs. We subtracted the total evaluation costs, as they were not intended to contribute to implementation. We aggregated the number of food service organisations reached and the number of people reached annually in implementation. We then combined cost and reach to estimate the recipient cost per food service organisation reached and per person reached as

Cost per food service organisation reached $=$ Total cost - Evaluation cost

$\overline{\text { Number of food service organisations reached }}$

Cost per person reached $=\frac{\text { Total cost }- \text { Evaluation cost }}{\text { Number of people reached }}$

These two metrics represent key implementation outcomes for recipients. Their primary goal is to recruit food service organisations to implement sodium reduction strategies and then catalyse change in those organisations to reach people with sodium reduction strategies.

We computed the average cost per food service organisation to implement each activity. Not all food service organisations engaged in all activities, so not all incurred costs related to each activity. We also computed total cost per person served to account for differences in size across food services organisations. For a subset of thirteen food service organisations, recipients reported organisation-specific data for the performance measure: number of items with lowered sodium through recipe modification or item or ingredient substitution. For this subset of food service organisations, we linked the performance measure data 
with the cost data and computed cost per food item affected as

Cost per item affected $=$

Total cost

Number of items affected by recipe modifcation or subsitution

The primary goal of food service organisations was to reduce sodium content of menu items, so this metric represents a summary of their activities. However, it is possible that total cost includes some costs related to activities not specifically aimed at reducing sodium content of food items (e.g. administrative meetings).

Long-term cost-effectiveness analysis

We used PRISM to simulate the potential long-term health outcomes and medical costs if reductions in sodium consumption are sustained. This modelling process included five steps: (1) generating estimates of the short-term programme effectiveness on reduced sodium consumption to be used as a model input, (2) estimating the long-term health gains and medical cost savings from sustained reduction in sodium consumption from SRCP, (3) estimating the long-term costs of sustaining sodium reduction strategies, (4) computing the cost-effectiveness ratio and (5) conducting sensitivity analysis of key assumptions.

(1) Generate an estimate of short-term programme effectiveness

The PRISM module for examining the impact of changes in average sodium consumption requires, as an input, the population-level reduction in average sodium consumption achieved across recipients which is computed as

$$
\begin{aligned}
\text { Population sodium reduction }= & \% \text { Targeted population reducing } \\
& \text { sodium intake } \times \text { average sodium } \\
& \text { reduction amongst population } \\
& \text { reached }
\end{aligned}
$$

It is important to include the percentage of people reducing sodium consumption as an input, because PRISM is a population model and models the impact across the entire target population. We took the values to compute this input from two short-term programme effectiveness performance measures reported by SRCP recipients: (1) percentage of people in the targeted food service organisation who purchased lower-sodium items (assumed to be the percentage of people reducing sodium consumption) and (2) change in average daily sodium intake as measured by nutritional analysis of items purchased at participating food service organisations conducted by the recipient. As noted above, the performance measure for the percentage of people reducing sodium consumption is based on sales data of the percentage of people that purchase lowersodium menu options. The food service organisations participating in SRCP serve largely the same customers every day, so this is a reasonable proxy.
The average percentage of people in the targeted population that purchased lower-sodium items was $20 \%$ across all reporting SRCP venues (ranging from 1 to $91 \%$ across venues), and the average reduction in sodium intake was $399 \mathrm{mg}$ per person across all reporting SRCP venues (ranging from 1 to $542 \mathrm{mg}$ across venues). Using these inputs in Equation (4) generates the PRISM input for the short-term effectiveness of the programme as $79 \mathrm{mg} / \mathrm{d}$ reduction in sodium consumption across the target population (i.e. $20 \% * 399 \mathrm{mg} / \mathrm{d}$ ).

(2) Estimate the long-term health gains and medical cost savings from SRCP

We used the estimate of the short-term effectiveness of SRCP as an input in PRISM to produce estimates of the impact of SRCP on per capita health and economic outcomes through 2025 and 2040, including quality-adjusted life-years (QALY), premature deaths and medical costs (medical expenditures). PRISM simulates the relationships between risk factors (e.g. high sodium intake), chronic disease (e.g. hypertension) and health outcomes (e.g. CVD events, deaths and medical costs) annually and cumulatively through 2025 and 2040. Because the model has been described in detail elsewhere ${ }^{(10-12,14)}$, we only focus on the aspects related to sodium in this paper. The model tracks average daily sodium consumption at the population level for a nationally representative population over time and simulates the impact of changes in sodium consumption on hypertension rates in the population. The model then simulates the impact of hypertension on CVD and medical costs, including costs related to hypertension management, CVD and event hospitalisation and care. Costs are all discounted by $3 \%$ annually to account for time preference (i.e. that the present is valued more than the future). Key model parameters related to hypertension and sodium are shown in Table 3. The impact of hypertension on CVD events is modelled using a modified version of the Framingham equation ${ }^{(15)}$. The original Framingham equation was modified for PRISM to (1) include additional risk factors such as secondhand smoke, fruit and vegetable intake, sodium intake, psychological distress and physical activity; (2) include risk adjustments for control of high blood pressure, high blood cholesterol and diabetes; (3) calibrate the CVD event and death rates by age, sex and event type (stroke, CHD and overall) to reported surveillance data; and (4) differentiate rates for first-time and subsequent CVD events. The model simulates changes in risk factors and outcomes over time with and without any intervention and compares the scenarios to estimate the impact of the intervention. PRISM has been validated over the course of its development ${ }^{(16)}$ and has been used to estimate the potential long-term impact and costeffectiveness of several other community prevention programmes, such as the Communities Putting Prevention to Work programme $(17,18)$ and the Community Transformation Grants programme ${ }^{(19)}$. Specific to the present paper, PRISM includes the ability to model 
Table 3 Key PRISM parameters related to sodium consumption, hypertension and CVD

\begin{tabular}{|c|c|c|}
\hline Model parameter & Value & Source \\
\hline $\begin{array}{l}\text { Reduction in SBP among the population without } \\
\text { hypertension per } 1000 \mathrm{mg} \text { sodium reduction }\end{array}$ & $1.0 \mathrm{~mm} \mathrm{Hg}$ & $\begin{array}{l}\text { Synthesis of Midgley et al. }{ }^{(20)} \text {, Cutler et al. }{ }^{(21)}, \mathrm{He} \text { and } \\
\text { MacGregor }{ }^{(22,23)} \text {, Yang et al }{ }^{(24)} \text {, He et al. }{ }^{(25)} \text {, Aburto et al. }{ }^{(26)} \text {, } \\
\text { Shi et al. }{ }^{(27)} \text {, Caldiera et al. }{ }^{(28)}\end{array}$ \\
\hline $\begin{array}{l}\text { Reduction in SBP among the population with } \\
\text { hypertension per } 1000 \mathrm{mg} \text { sodium reduction }\end{array}$ & $2.75 \mathrm{~mm} \mathrm{Hg}$ & $\begin{array}{l}\text { Synthesis of Midgley et al. }{ }^{(20)} \text {, Cutler et al. }{ }^{(21)}, \text { He and } \\
\text { MacGregor }{ }^{(22,23)} \text {, Yang et al.(24), He et al. }{ }^{(25)} \text {, Aburto et al. }{ }^{(26)} \text {, } \\
\text { Shi et al. }{ }^{(27)} \text {, Caldiera et al. }{ }^{(28)}\end{array}$ \\
\hline $\begin{array}{l}\text { Reduction in CVD events }{ }^{*} \text { and deaths from changes } \\
\text { in hypertension }\end{array}$ & $\begin{array}{l}\text { Framingham } \\
\text { equation }\end{array}$ & Anderson et al. ${ }^{(15)}$ \\
\hline $\begin{array}{l}\text { Annual per person cost of hypertension } \\
\text { management }(2018 \$)\end{array}$ & $\$ 564$ & MEPS 2003-05 (regression analysis) \\
\hline $\begin{array}{l}\text { Annual acute care and rehab costs of a survived } \\
\text { CVD event* }(2018 \$)\end{array}$ & $\$ 32640$ & $\begin{array}{l}\text { Russell et al. }{ }^{(29)} \text {, Carlson et al. }{ }^{(30)} \text {, expert opinion of stroke } \\
\text { subject matter experts at Veterans Health Administration, } \\
\text { Fox et al.. }\end{array}$ \\
\hline $\begin{array}{l}\text { Annual acute care costs of a non-sudden death from } \\
\text { a CVD event }{ }^{\star}(2018 \$)\end{array}$ & $\$ 34643$ & Russell et al. ${ }^{(29)}$ \\
\hline $\begin{array}{l}\text { Annual acute care costs of a sudden death from a } \\
\text { CVD event }{ }^{*}(2018 \$)\end{array}$ & $\$ 1409$ & Russell et al. ${ }^{(29)}$ \\
\hline $\begin{array}{l}\text { Average hospitalisation cost of non-CVD† } \\
\text { complications of hypertension }(2018 \$)\end{array}$ & $\$ 11910$ & $\begin{array}{l}\text { Average hospitalisation cost of hypertension: HCUP, } 2016 . \\
\text { ICD-10: I10 (primary hypertension) and I12 (hypertensive } \\
\text { CKD) }\end{array}$ \\
\hline
\end{tabular}

SBP, systolic blood pressure; PRISM, Prevention Impacts Simulation Model; CKD, chronic kidney disease; HCUP, Healthcare Cost and Utilization Project; ICD10 , International Classification of Diseases, 10th Revision; MEPS, Medical Expenditure Panel Survey.

${ }^{*} \mathrm{CVD}$ events include CHD, heart failure and stroke.

†Non-CVD complications of hypertension include primary hypertension and kidney disease.

interventions for reducing average sodium consumption in the population.

(3) Estimate the long-term costs of sustaining sodium reduction strategies

PRISM uses the costs per capita for start-up and for ongoing maintenance as inputs. The costs measured in the cost study represent per capita implementation costs for the first 36 months of the programme from recipients and food service organisations. We assumed that this represents the start-up period of the programme. We also assumed that the average cost per capita for the included food service organisations is representative of food service organisations across the programme. Because we only collected implementation cost data during the start-up period, we assumed that the ongoing maintenance costs would be $95 \%$ of start-up costs. This is based on subject matter expert opinion that policy and systems interventions such as these have minimal ongoing maintenance costs, $10 \%$ of start-up (M. Farrelly, personal communication, June 2012). Annual start-up costs used in the model were $\$ 2.02$ per capita, including costs of recipients and food service organisations. Ongoing maintenance costs were $\$ 0 \cdot 20$.

(4) Compute the cost-effectiveness ratio

To assess the long-term cost-effectiveness, we computed

$$
\begin{aligned}
& \text { Cost-efectiveness ratio }= \\
& \frac{(\text { Program costs }- \text { Medical cost cavings })}{\text { Health impact }}
\end{aligned}
$$

This ratio represents the cost per health impact achieved. It can be thought of as measuring the programme's return on investment. We measured health impact in terms of both premature deaths averted and QALY gained. To draw conclusions from the cost-effectiveness ratio, it is necessary to compare it with estimates of societal willingness to pay for health gains. If the cost-effectiveness ratio is lower than societal willingness to pay, then it can be considered costeffective. If the cost-effectiveness ratio is greater than societal willingness to pay, then the programme is considered not cost-effective. A conservative and common threshold of willingness to pay in the USA is $\$ 50000$ per QALY saved ${ }^{(32)}$. We conducted a probabilistic sensitivity analysis to generate $95 \%$ CI for the estimates.

(5) Conduct sensitivity analysis of key assumptions

We conducted one-way sensitivity analysis to test the sensitivity of results to two key assumptions in the model: (1) programme effectiveness and (2) the ongoing implementation costs to maintain the intervention. Specifically, we examined the change in net costs if effectiveness was reduced by $50 \%$ and if maintenance costs were 50 or $100 \%$ of start-up implementation cost.

\section{Results}

The average total implementation cost of SRCP recipients was $\$ 1264609$, with low variation $(\mathrm{SD}=\$ 204819)$ (Table 4). The most cost-intensive activity for recipients on average was conducting evaluation, but implementing sodium reduction interventions was nearly as costly. There was low variation across all cost categories for recipients with all SD being less than half of the mean. Total monthly costs incurred by SRCP food service organisations averaged $\$ 4282$ but varied substantially, ranging from $\$ 88$ 
Table 4 Average SRCP recipient implementation cost (30 September 2016-29 September 2019), by activity

\begin{tabular}{|c|c|c|c|c|c|}
\hline Activity & $n$ & Mean & SD & Min & Max \\
\hline Building and maintaining partnerships & 8 & $\$ 201401$ & $\$ 45743$ & $\$ 116265$ & $\$ 263584$ \\
\hline Designing sodium reduction interventions & 8 & $\$ 183180$ & $\$ 52091$ & $\$ 109586$ & $\$ 243625$ \\
\hline Implementing sodium reduction interventions & 8 & $\$ 292040$ & $\$ 80905$ & $\$ 198849$ & $\$ 450409$ \\
\hline Conducting evaluation & 8 & $\$ 311628$ & $\$ 103480$ & $\$ 182895$ & $\$ 533654$ \\
\hline Performing administrative activities & 8 & $\$ 276359$ & $\$ 88875$ & $\$ 135493$ & $\$ 380532$ \\
\hline Total & 8 & $\$ 1264609$ & $\$ 204819$ & $\$ 1008240$ & $\$ 1603550$ \\
\hline
\end{tabular}

Table 5 Average monthly implementation cost to food service organisations by activity

\begin{tabular}{|c|c|c|c|c|c|}
\hline Activity & $n$ & Mean & SD & Min & Max \\
\hline Total cost & 20 & $\$ 4282$ & $\$ 6790$ & $\$ 88$ & $\$ 28747$ \\
\hline Total cost per person served & 17 & $\$ 2$ & $\$ 4$ & $\$ 1$ & $\$ 19$ \\
\hline Cooking for new product offerings & 6 & $\$ 1964$ & $\$ 2990$ & $\$ 27$ & $\$ 7886$ \\
\hline Nutritional analysis and recipe development & 15 & $\$ 1648$ & $\$ 3370$ & $\$ 39$ & $\$ 13047$ \\
\hline $\begin{array}{l}\text { Healthy food promotion, including environmental and behavioural } \\
\text { economic interventions }\end{array}$ & 12 & $\$ 1126$ & $\$ 2325$ & $\$ 19$ & $\$ 8062$ \\
\hline Other activities related to development & 7 & $\$ 1061$ & $\$ 1326$ & $\$ 15$ & $\$ 3341$ \\
\hline Find new lower-sodium ingredients & 14 & $\$ 941$ & $\$ 2342$ & $\$ 11$ & $\$ 8933$ \\
\hline Meetings & 12 & $\$ 596$ & $\$ 787$ & $\$ 11$ & $\$ 2399$ \\
\hline Other activities & 3 & $\$ 494$ & $\$ 404$ & $\$ 169$ & $\$ 947$ \\
\hline Nutrition guideline implementation & 13 & $\$ 432$ & $\$ 952$ & $\$ 5$ & $\$ 3563$ \\
\hline Trainings for new recipes or techniques & 12 & $\$ 64$ & $\$ 81$ & $\$ 3$ & $\$ 296$ \\
\hline
\end{tabular}

Table 6 Implementation cost-effectiveness measures

\begin{tabular}{|c|c|c|c|c|c|c|}
\hline Cost-effectiveness metric & $n^{*}$ & Mean & SD & Median & Min & Max \\
\hline \multicolumn{7}{|l|}{ Recipient level } \\
\hline Cost per person reached & 8 & $\$ 10$ & $\$ 10$ & $\$ 6$ & & $\$ 28$ \\
\hline Cost per food service organisation reached & 8 & $\$ 42917$ & $\$ 37343$ & $\$ 36623$ & $\$ 5308$ & $\$ 122316$ \\
\hline \multicolumn{7}{|l|}{ Food service organisation level } \\
\hline $\begin{array}{l}\text { Monthly cost per item affected by recipe modification or product } \\
\text { substitution }\end{array}$ & 13 & $\$ 22869$ & $\$ 54290$ & $\$ 684$ & $\$ 3$ & $\$ 183979$ \\
\hline
\end{tabular}

${ }^{*}$ At the recipient level, $\mathrm{N}$ represents the number of recipients that reported both cost data and the performance measure data. At the food services organisation level, $\mathrm{N}$ represents the number of food service organisations that reported both cost data and performance measure data.

to $\$ 28747$ (Table 5). Most of this variation was eliminated when considering the cost per person served at the food service organisation. After constructing this measure, only one outlier (more than $3 \mathrm{SD}$ above the mean) remained, and the rest of the values were within a consistent range. This organisation was implementing major recipe changes. The most cost-intensive activity for food service organisations on average was additional food preparation, but only six of the food service organisations reported conducting this activity, and their costs varied widely (\$27-\$7886). The next most-costly activities were nutritional analysis and recipe development (\$1648) and healthy food promotion (\$1126), both of which were common activities among partners (conducted by fifteen and twelve partners, respectively).

Table 6 shows estimates of the cost of implementation achievements at both the recipient and food service organisation levels. At the recipient level, cost per person reached averaged $\$ 10$, and cost per food service organisation reached averaged $\$ 42917$. Both metrics had moderate variation, with SD near the mean estimates. Median values were $\$ 6$ and $\$ 36623$, respectively. At the food service organisation level, monthly cost per item affected by recipe modification or product substitution averaged $\$ 22869$, but this average was driven by one outlier ( $\$ 183$ 979); the median was only $\$ 684$. This outlier was an organisation that had incurred substantial implementation costs but had not yet impacted many menu items.

Table 7 presents estimates of the potential long-term cost-effectiveness of SRCP through 2025 and 2040. If changes made are sustained through 2025, the activities implemented under SRCP are projected to decrease premature deaths by $0 \cdot 17 \%$ and medical costs by $0 \cdot 12 \%$ and increase QALY by $0.77 \%$ cumulatively over the entire period among the populations targeted by SRCP recipients. When examining the cost-effectiveness of these impacts, 
Table 7 Long-term cost-effectiveness of SRCP through 2025 and $2040^{*}$

\begin{tabular}{|c|c|c|c|c|}
\hline \multirow[b]{2}{*}{ Metric } & \multicolumn{2}{|c|}{2025} & \multicolumn{2}{|c|}{2040} \\
\hline & Mean & $95 \% \mathrm{Cl}$ & Mean & $95 \% \mathrm{Cl}$ \\
\hline $\begin{array}{l}\text { Percentage change in premature deaths in the target } \\
\text { population }\end{array}$ & $-0.17 \%$ & $-0.14 \%,-0.29 \%$ & $-0.19 \%$ & $-0.16 \%,-0.31 \%$ \\
\hline $\begin{array}{l}\text { Percentage change in average annual QALY per capita in } \\
\text { the target population }\end{array}$ & $0.77 \%$ & $0.64 \%, 1.25 \%$ & $0.91 \%$ & $0.75 \%, 1.45 \%$ \\
\hline $\begin{array}{l}\text { Percentage change in medical costs in the target } \\
\text { population }\end{array}$ & $-0.12 \%$ & $-0.09 \%,-0.21 \%$ & $-0.14 \%$ & $-0.11 \%,-0.24 \%$ \\
\hline $\begin{array}{l}\text { Net cost per capita in the target population }(2018 \$ \text { ) } \\
\text { Cost-effectiveness ratio per premature death averted } \\
\text { Cost-effectiveness ratio per quality-adjusted life-year gained }\end{array}$ & $\begin{array}{l}-\$ 1 \cdot 82 \\
\text { Cost saving } \\
\text { Cost saving }\end{array}$ & $-\$ 1 \cdot 69,-\$ 1 \cdot 88$ & $\begin{array}{l}-\$ 2 \cdot 09 \\
\text { Cost saving } \\
\text { Cost saving }\end{array}$ & $-\$ 1 \cdot 97,-\$ 2 \cdot 23$ \\
\hline
\end{tabular}

*(1) Target population is the total population in the food service organisations targeted by SRCP. (2) Estimates were generated using PRISM's nationally representative model and measures of SRCP programme implementation and costs. (3) Estimates are for the entire population aged $2+$ years.

Table 8 One-way sensitivity analysis of change key assumptions on net-cost per capita of SRCP through 2025 and 2040*

\begin{tabular}{lcc}
\hline Change in assumption & 2025 & 2040 \\
\hline $50 \%$ reduction in programme effectiveness & $-\$ 0.61$ & $-\$ 0.41$ \\
$\begin{array}{l}\text { Maintenance costs are } 50 \% \text { of start-up } \\
\text { implementation costs }\end{array}$ & $-\$ 1.27$ & $-\$ 1.24$ \\
$\begin{array}{l}\text { Maintenance costs are } 100 \% \text { of start-up } \\
\text { implementation costs }\end{array}$ & $-\$ 0.58$ & $-\$ 0.19$ \\
\hline
\end{tabular}

*(1) Target population is the total population in the food service organisations targeted by SRCP. (2) Estimates were generated using PRISM's nationally representative model and measures of SRCP programme implementation and costs. (3) Estimates are for the entire population aged $2+$ years.

the programme is cost saving, indicating that cumulative medical cost savings through 2025 are greater than cumulative programme costs. If sustained through 2040, the activities implemented under SRCP are projected to decrease deaths by $0.19 \%$ and medical costs by $0.14 \%$ and increase QALY by $0.91 \%$ cumulatively over the entire period among the populations targeted by SRCP recipients. When examining the cost-effectiveness of these impacts, the programme is cost saving, indicating that cumulative medical cost savings through 2040 are greater than cumulative programme costs.

Table 8 presents one way sensitivity analysis testing the impact of changes in assumptions on the projected impact on per capita net costs through 2025 and 2040. A $50 \%$ reduction in programme effectiveness was estimated to reduce the cost savings of the programme, but net costs were still negative indicating the programme is still projected to be cost saving. After increasing maintenance cost of the programme to 50 and $100 \%$ of start-up implementation cost, the programme is still projected to be cost saving, although the amount saved per capita was reduced.

\section{Discussion}

We evaluated the costs and outcomes of the first 3 years of the 2016-2021 round of SRCP (September 2016-September
2019). We estimated the costs of achieving programme implementation goals and found that at the recipient level, cost per person reached averaged $\$ 10$, and cost per food service organisation reached averaged $\$ 42917$. At the food service organisation level, monthly cost per item affected by recipe modification or product substitution had a median of $\$ 684$. We also estimated the cost-effectiveness of SRCP through 2025 and 2040. Results demonstrate that SRCP strategies are projected to be cost saving through 2025 and 2040 if the sodium reduction observed in programme performance measures is sustained. The health impacts were not large, but the programme costs are projected to be offset by medical cost savings over time. Furthermore, the health impact could be greater if scaled across a larger population (e.g. the population reached by SRCP was 3.9 million and $20 \%$ reduced sodium consumption). The simulated reduction in sodium intake represented $6 \%$ of the reduction needed to reach the recommended daily intake of $2300 \mathrm{mg}^{(5)}$. This average population level reduction is in line with the average reduction across studies identified in a recent systematic review $^{(33)}$. Understanding the cost of public health programmes and the long-term impacts are key to include in a larger framework for public health decisions and chronic disease prevention ${ }^{(34)}$. The results highlight how sodium reduction strategies can impact health and healthcare cost over time. Programme implementation costs are primarily incurred at the outset, and once changes are in place (e.g. lower-sodium options available), the impact can compound over time with potential cost savings by 2025. However, it is important to note that programme costs are born by public health agencies while the medical cost savings accrue to individuals, payers and health systems.

Previous studies have used simulation models to examine the potential impact of hypothetical changes in sodium intake with no consideration of strategies to achieve the hypothetical changes ${ }^{(35-38)}$. One study examined hypothetical strategies for achieving sodium reduction in the USA, estimating that a government-led collaboration with food manufacturers to reduce sodium content would 
increase life-years by 1.3 million and save $\$ 32.1$ billion in lifetime medical costs and a sodium tax would increase life-years by 840113 and save $\$ 22.4$ billion in lifetime medical costs ${ }^{(39)}$. However, the assumptions about the efficacy of strategies used in the study are not drawn from practice-based evidence in the USA and implementation costs are not considered. Other studies have simulated the cost-effectiveness of strategies implemented in other countries, such as the United Kingdom and New Zealand, and estimated approaches to be either cost-effective or cost-saving ${ }^{(40,41)}$. The results of this study add to the evidence base by demonstrating what a public health intervention can achieve and incorporating implementation costs for a small set of sodium reduction strategies.

Analysis of the cost of achieving implementation outcomes provides insight into the return on programme inputs, demonstrating how much was achieved for investments, and assists in planning for other organisations seeking to implement similar sodium reduction strategies. There was moderate variation in the recipient cost per person and food service organisation reached, which may be driven by differences in venues that may be more likely to serve more people less frequently (e.g. hospitals) or fewer people more frequently (e.g. congregate meals). This variation is an important consideration for planners seeking to budget sufficiently to achieve programme goals in targeted venues.

Results also highlight the important contributions of partner food service organisations. Past studies have assumed that food service organisations would not incur any additional costs to make recipe modifications or product substitutions because it is part of normal reformulation operations ${ }^{(39)}$. However, the results of this study provide contradictory evidence, demonstrating that food service organisations do incur costs on a range of activities, including recipe modification, procurement changes and overall coordination. This finding is important when considering the feasibility of these sodium reduction strategies because food service organisations may be reluctant to partner given the costs. Other studies of SRCP have shown the importance of external and internal factors to generate buy-in for sodium reduction efforts ${ }^{(42)}$, which are important for overcoming potential cost concerns. Cost per menu item affected was relatively consistent across food service organisations after accounting for one large outlier that had incurred substantial cost but had yet to achieve any impact, indicating that results may be useful across a range of organisations implementing sodium reduction strategies. Partners from seven of the eight venues submitted cost data, but the highest participation rate was from congregate meals and there was not a clear pattern across the other venues. This may impact results if the probability of response was correlated with lower or higher costs.

This study has several limitations. First, we assumed that we are reducing sodium consumption daily in a consistent population, meaning all of the consumers frequenting these food service organisations eat at these venues daily.
We tested this assumption in sensitivity analysis where we reduced the effectiveness measure by $50 \%$. In this analysis, the impact was reduced, but the net effect was still cost saving. Simulations were cost saving up to a $75 \%$ reduction in the effectiveness input. This assumption allows us to estimate a population-level effect. However, we know that at least some of these food service organisations do not have consistent patrons. Similarly, reach is likely not representative of community populations, and we do not have information on how populations at a higher risk for CVD (e.g. those with high blood pressure or other risk factors) were affected. Second, we assume that changes are sustained through 2025 and 2040, which may not be reasonable because organisations might revert to using higher-sodium recipes or products. Third, PRISM uses a nationally representative population to produce estimates of percentage changes in outcomes. The SRCP target population may not reflect this same population mix, which would impact results. Implementation and effectiveness measures reported by recipients were not reported by all organisations for all venues, so we assumed that measures of the percentage of people reducing sodium intake and the average sodium content of foods were generalisable to all organisations and venues. Further, they are only performance measures and may not represent the causal impact of the programme. Fourth, cost data were collected retrospectively and may be subject to recall bias. Fifth, the partner food service organisations that participated in the cost study were a convenience sample, subject to nonresponse, and our findings may not be generalisable to all SRCP partner food service organisations. Finally, simulation modelling results are limited by the availability and quality of evidence in the literature. PRISM is based on the latest evidence and has been tested and validated extensively but it is subject to these standard model limitations.

By providing evidence of the cost-effectiveness of a public health sodium reduction initiative, this study is an important advance in the literature on the cost-effectiveness of sodium reduction strategies. Community-level nutrition interventions that augment the amounts of microand macro-nutrients in foods that people consume without having to change their behaviour have been shown to play a key role in improving population health (e.g. folic acid fortification of foods $\left.{ }^{(43)}\right)$. Community-level change is not easy to achieve, but the success can be substantial and takes the onus off consumers who may not be tracking the nutrient content or who may have constrained options. In food fortification examples, success happened after food fortification policies and standards were set by the US Food and Drug Administration. However, similar to SRCP, food fortification started as a voluntary opt-in by food producers. Sodium reduction strategies at the food service organisation level provide an opportunity to make changes to the amount of a nutrient the population consumes and can affect real health outcomes ${ }^{(44)}$. The findings here represent 
the current state of implementation but if these efforts could be scaled up, the average daily amount of sodium consumed by US adults could be brought closer to the recommended amount in the dietary guidelines. The results of this study demonstrate the long-term cost-effectiveness of SRCP, which can catalyse future work in sodium reduction and promote scale-up to achieve this impact. Furthermore, the results demonstrate the costs of achieving implementation goals that can support effective planning for future programmes, ensuring that budgets are sufficient to achieve impact.

\section{Acknowledgements}

Acknowledgements: The authors would like to thank SRCP recipients and participating food service organisations for providing the data used in this study. Financial support: This manuscript was prepared by RTI International, under contract 200-2014-61263 to the Centers for Disease Control and Prevention. The findings and conclusions of this manuscript are those of the authors and do not represent the official position of the Centers for Disease Control and Prevention. Conflict of interest: There are no conflicts of interest. Authorship: B.Y. led the study and led manuscript development. E.T., K.M., J.W. and J.J. provided study oversight and contributed to reviewing and revising the manuscript. C.B. and Z.T. conducted the analysis. Ethics of buman subject participation: The RTI IRB reviewed this study and determined it not to be human subjects research.

\section{References}

1. Zhang Z, Cogswell ME, Gillespie C et al. (2013) Association between usual sodium and potassium intake and blood pressure and hypertension among US adults: NHANES 20052010. PLOS ONE 8, e75289.

2. Cook NR, Appel LJ \& Whelton PK (2014) Lower levels of sodium intake and reduced cardiovascular risk. Circulation 129, 981-989.

3. Cogswell ME, Loria CM, Terry AL et al. (2018) Estimated 24hour urinary sodium and potassium excretion in US adults. JAMA 319, 1209-1220.

4. U.S. Department of Agriculture \& U.S. Department of Health and Human Services (2020) Dietary Guidelines for Americans, 2020-2025, 9th ed.; available at DietaryGuidelines.gov (accessed July 2021).

5. National Academies of Sciences Engineering and Medicine (2019) Dietary Reference Intakes for Sodium and Potassium. Washington, DC: National Academies Press.

6. Boon CS, Taylor CL \& Henney JE (2010) Strategies to Reduce Sodium Intake in the US. Washington, DC: National Academies Press.

7. Food and Drug Administration (2016) Draft Guidance for Industry: Voluntary Sodium Reduction Goals: Target Mean and Upper Bound Concentrations for Sodium in Commercially Processed, Packaged, and Prepared Foods. Silver Spring, MD: Food and Drug Administration.
8. Regulations.gov (2016) Comment from Grocery Manufacturers Association. No. FDA-2014-D-0055-0425. Washington, DC: Grocery Manufacturers Association.

9. Jordan J, Hickner H, Whitehill J et al. (2020) CDC's sodium reduction in communities program: evaluating differential effects in food service settings, 2013-2016. Preventing Chronic Dis 17, E72.

10. Homer J, Milstein B, Labarthe D et al. (2010) Simulating and evaluating local interventions to improve cardiovascular health. Prev Chronic Dis 7, A18.

11. Hirsch G, Homer J, Trogdon J et al. (2014) Using simulation to compare 4 categories of intervention for reducing cardiovascular disease risks. Am J Public Health 104, 1187-1195.

12. Hirsch G, Homer J, Evans E et al. (2010) A system dynamics model for planning cardiovascular disease interventions. Am J Public Health 100, 616-622.

13. Canby JB (1995) Applying activity-based costing to healthcare settings. Healthcare financial manage. J Healthc Financ Manage Assoc 49, 50.

14. Orenstein DR, Homer J, Milstein B et al. (2008) Modeling the local dynamics of cardiovascular health: risk factors, context, and capacity. Prev Chronic Dis 5, A63.

15. Anderson KM, Odell PM, Wilson PWF et al. (1991) Cardiovascular disease risk profiles. Am Heart J 121, 293-298.

16. Honeycutt A, Yarnoff B, Khavjou O et al. (2021) Validation of the prevention impact simulation model. Prev Chronic Dis 18.

17. Soler R, Orenstein D, Honeycutt A et al. (2016) Communitybased interventions to decrease obesity and tobacco exposure and reduce health care costs: outcome estimates from communities putting prevention to work for 2010-2020. Prev Chronic Dis 13, E47.

18. Honeycutt A, Bradley C, Khavjou O et al. (2019) Simulated impacts and potential cost effectiveness of communities putting prevention to work: tobacco control interventions in 21 US communities, 2010-2020. Prev Med 120, 100-106.

19. Yarnoff B, Bradley C, Honeycutt AA et al. (2019) Estimating the relative impact of clinical and preventive communitybased interventions: an example based on the community transformation grant program. Preventing Chronic Dis 16, E87.

20. Midgley JP, Matthew AG, Greenwood CMT et al. (1996) Effect of reduced dietary sodium on blood pressure: a meta-analysis of randomized controlled trials. JAMA $\mathbf{2 7 5}$, 1590-1597.

21. Cutler JA, Follmann D \& Allender PS (1997) Randomized trials of sodium reduction: an overview. Am J Clin Nutr $\mathbf{6 5}$, 643S-651S.

22. He FJ \& MacGregor GA (2002) Effect of modest salt reduction on blood pressure: a meta-analysis of randomized trials. Implications for public health. JHum Hypertens 16, 761-770.

23. He FJ \& MacGregor GA (2013) Effect of longer-term modest salt reduction on blood pressure. Cochrane Database Syst Rev 4.

24. Yang Q, Zhang Z, Kuklina EV et al. (2012) Sodium intake and blood pressure among US children and adolescents. Pediatrics 130, 611-619.

25. He FJ, Marrero NM \& MacGregor GA (2008) Salt and blood pressure in children and adolescents. J Hum Hypertens 22, 4-11.

26. Aburto NJ, Ziolkovska A, Hooper L et al. (2013) Effect of lower sodium intake on health: systematic review and meta-analyses. BMJ 346, f1326.

27. Shi L, Krupp D \& Remer T (2014) Salt, fruit and vegetable consumption and blood pressure development: a longitudinal investigation in healthy children. Br J Nutr 111, 662-671.

28. Caldeira D, Vaz-Carneiro A \& Costa J (2013) What is the benefit of salt reduction on blood pressure? Assessment of the 
Cochrane Review: effect of longer-term modest salt reduction on blood pressure. Cochrane Database Syst Rev 4, CD004937.

29. Russell MW, Huse DM, Drowns S et al. (1998) Direct medical costs of coronary artery disease in the US. Am J Cardiol 81, $1110-1115$.

30. Carlson JJ, Johnson JA, Franklin BA et al. (2000) Program participation, exercise adherence, cardiovascular outcomes, and program cost of traditional $v$. modified cardiac rehabilitation. Am J Cardiol 86, 17-23.

31. Fox KM, Wang L, Gandra SR et al. (2016) Clinical and economic burden associated with cardiovascular events among patients with hyperlipidemia: a retrospective cohort study. Bmc Cardiovasc Disor 16, 13.

32. Neumann PJ, Cohen JT \& Weinstein MC (2014) Updating cost-effectiveness - the curious resilience of the $\$ 50000$ per-QALY threshold. N Engl J Med 371, 796-797.

33. Barberio AM, Sumar N, Trieu K et al. (2017) Populationlevel interventions in government jurisdictions for dietary sodium reduction: a Cochrane Review. Int J Epidemiol 46, 1551-1405.

34. Frieden TR (2010) A framework for public health action: the health impact pyramid. Am J Public Health 100, 590-595.

35. Bibbins-Domingo K, Chertow GM, Coxson PG et al. (2010) Projected effect of dietary salt reductions on future cardiovascular disease. $N$ Engl J Med 362, 590-599.

36. Polar K \& Sturm R (2009) Potential societal savings from reduced sodium consumption in the US adult population. Am J Health Promot 24, 49-57.
37. Doll TM, Fulgoni VL, Zhang Y et al. (2009) Potential health benefits and medical cost savings from calorie, sodium, and saturated fat reductions in the American diet. $\mathrm{Am} \mathrm{J}$ Health Promot 23, 412-422.

38. Coxson PG, Cook NR, Joffres M et al. (2013) Mortality benefits from US population-wide reduction in sodium consumption: projections from 3 modeling approaches. Hypertension 61, 564-570

39. Smith-Spangler CM, Juusola JL, Enns EA et al. (2010) Population strategies to decrease sodium intake and the burden of cardiovascular disease: a cost-effectiveness analysis. Ann Intern Med 152, 481-487.

40. Nghiem N, Blakely T, Cobiac LJ et al. (2015) Health and economic impacts of eight different dietary salt reduction interventions. PLOS ONE 10, e0123915.

41. Wilson N, Nghiem N, Eyles H et al. (2015) Modeling health gains and cost savings for ten dietary salt reduction targets. Nutr J 15, 44 .

42. Strazza K, Whitehill J, Jordan J et al. (2021) Implementing strategies to address health equity in the context of limited resources? Examples from charitable food organizations participating in the sodium reduction in communities program. Am J Health Promot (In Press).

43. Honein MA, Paulozzi LJ, Mathews TJ et al. (2001) Impact of folic acid fortification of the US food supply on the occurrence of neural tube defects. JAMA 285, 2981-2986.

44. Insitute of Medicine (2010) Strategies to Reduce Sodium Intake in the US. Washington, DC: National Academies Press. 